\title{
A Internacionalização da Língua Portuguesa em tempo de crise da Covid-19: Educação e Cenário Globalizado
}

\author{
Rosana Helena Nunes ${ }^{1}$ \\ Faculdade de Tecnologia do Estado de São Paulo (FATEC/SP) e Universidade de Brasília (UnB), Brasília, DF, Brasil \\ Kleber Aparecido da Silva ${ }^{2}$ \\ Universidade de Brasília (UnB) Brasília, DF, Brasil
}

Resumo: O texto discute a questão da internacionalização da Língua Portuguesa, como língua adicional, no cenário da globalização, e a diversidade linguística. A Língua Portuguesa tem atingido um patamar no ranking de línguas mais faladas no mundo, o que permite pensar em internacionalização da língua. $\mathrm{O}$ artigo apresenta três partes. Na primeira parte, a globalização em tempo de crise da Covid-19 e o modo de produção capitalista. A segunda, as cinco políticas (PENNYCOOK, 1998; 1999; 2001) para elucidar o estatuto da língua em contexto de globalização e internacionalização. Na terceira, a Língua Portuguesa, como ferramenta de contato entre diferentes povos, em tempo de crise. E, por fim, a proposta de uma pedagogia humanizadora no ensino de Língua Portuguesa. A pesquisa fundamenta-se em Pennycook (1998; 1999; 2001); Calvet (2007); Freire (1987; 1997); Nunes (2019); Santos (2020); Oliveira (2008; 2013).

Palavras-chave: Internacionalização da língua portuguesa; Tempo de crise da COVID-19; Cenário globalizado.

Title: The Internationalization of the Portuguese Language in a time of crisis at Covid-19: Education and the Globalized Landscape

Abstract: The text discusses the question of the internationalization of the Portuguese language, as an additional language, in the globalization scenario, and linguistic diversity. The Portuguese language has reached a level in the ranking of most spoken languages in the

\footnotetext{
${ }^{1}$ Rosana Helena Nunes possui Pós-Doutorado em Educação (UNICAMP/SP), Doutorado em Língua Portuguesa (PUC/SP), Mestrado em Linguística Aplicada e Estudos de Linguagem (PUC/SP). Atua como professora de Ensino Superior Tecnológico, em Língua Portuguesa, na Faculdade de Tecnologia do estado de São Paulo (FATEC/SP). Desenvolve um estágio supervisionado em pós-doutorado pela Universidade de Brasília (UnB) sob a supervisão do Prof. Dr. Kleber Aparecido da Silva. Orcid: https://orcid.org/0000-0003-1800-3296. E-mail: rosananunes03@gmail.com.

${ }^{2}$ Kleber Aparecido da Silva possui Pós-Doutorado em Linguística Aplicada pela UNICAMP; em Linguística Aplicada e Estudos da Linguagem pela PUC-SP; em Linguística pela Universidade Federal de Santa Catarina (UFSC). Doutor em Estudos Linguísticos pela UNESP (São José do Rio Preto). Mestre em Linguística Aplicada pela UNICAMP. É professor associado 1 do Departamento de Linguística, Português e Línguas Clássicas e do Programa de Pós-Graduação em Linguística do Instituto de Letras da Universidade de Brasília (UnB), do Programa de Pós-Graduação em Letras: Cultura, Educação e Linguagens da Universidade Estadual do Sudoeste da Bahia e do Programa de Pós-Graduação em Letras da Universidade Federal de Tocantins - Campus de Porto Nacional. Coordenador do Grupo de Estudos Críticos e Avançados em Linguagens (GECAL/CNPq-UnB). Orcid: https://orcid.org/0000-0002-7815-7767. E-mail: kleberunicamp@yahoo.com.br.
} 
world, which allows thinking about internationalization of the language. The article has three parts. In the first part, the globalization in time of crisis of Covid-19 and the capitalist mode of production. The second, the five policies (PENNYCOOK, 1998; 1999; 2001) to clarify the status of the language in the context of globalization and internationalization. In the third, the Portuguese language, as a contact tool between different peoples, in times of crisis. And, finally, the proposal of a humanizing pedagogy in the teaching of Portuguese Language. The research is based on Pennycook (1998; 1999; 2001); Calvet (2007); Freire (1987; 1997); Nunes (2019); Santos (2020), and Oliveira (2008; 2013).

Keywords: internationalization of the Portuguese language; Times of crisis for COVID-19; Globalized scenario.

\section{Introdução}

O cenário globalizado traz implicações no que tange às condições econômicas, culturais, históricas etc. A era globalizada traz como exigência maior domínio de mercado e isso implica na concorrência, o que equivale dizer um domínio de diferentes idiomas que representam um grau de importância para melhor relacionar-se ao contexto mundial. Essa difusão dos mercados representou o avanço da economia mundial o que propiciou o processo de inovações tecnológicas, sobretudo, os de telecomunicações e informática. Isso implica também na forma pela qual a língua é vista no contexto da globalização.

Estudiosos da linguagem, como Calvet (2007), Pennycook (1998; 1999; 2001) e Oliveira (2008;2013), admitem que a internacionalização da língua tem alcançado uma ascensão quando se fala de sociedade e suas implicações com relação ao estudo de idiomas. Calvet (2007) ressalta a ligação entre língua e poder e as relações históricas e sociais das línguas, estabelecendo em seus trabalhos uma relação permanente entre teoria e prática. Pennnycook, ao referir-se à língua inglesa, também reconhece que a aprendizagem de línguas ainda se relaciona à manutenção das desigualdades sociais, estabelecendo as relações de poder entre língua e sociedade.

Oliveira (2013), em estudos a respeito da língua portuguesa no mundo globalizado do século XXI, desenvolve pesquisas sobre plurilinguismo, política linguística e internacionalização. $O$ autor reconhece que a língua portuguesa representa a primeira das línguas, desde a época das Grandes Navegações, época datada dos séculos XV e XVII, o que correspondeu ao período do processo colonial. Segundo o estudioso, o português se tornou a língua oficial em 10 países, oito destes países são membros da Comunidade dos Países de Língua Portuguesa (CPLP). O autor admite que o potencial do português, como língua internacional, é pouco explorado, sobretudo o português do Brasil, dado o plurilinguismo funcional presente no país.

Fala-se em "língua brasileira" ou "português do Brasil" e percebe-se ainda a predominância por adotar uma postura colonialista com relação à denominação "língua brasileira". Sabe-se que o Brasil apresenta uma heterogeneidade linguística, originária do processo de colonização, em que as diferenças "línguas" se fizeram presentes, quando do processo de miscigenação. A "língua do colonizador" ainda está presente a representar a 
identidade de um país com uma diversidade linguística e tamanha especificidade cultural e histórica.

Em 1753, Marques de Pombal determinou a língua portuguesa como língua nacional do país. Com a Constituição de $1988^{3}$, a língua portuguesa passa a tornar-se o idioma oficial do Brasil. E como pensar o plurilinguismo existente no país, ou seja, a "brasilidade do idioma da língua portuguesa", nas suas características próprias? E ainda, como reconhecer essa brasilidade da língua frente ao mundo globalizado, ao acreditar que o português do Brasil pode representar uma ferramenta de fundamental importância para a comunicação entre diferentes nacionalidades e estabelecer relações políticas, culturais e econômicos entre os povos?

Assim, a primeira parte do artigo, tratar-se-á da globalização em tempo de crise da Covid-19, como forma de mostrar o modo de produção capitalista, na condição de força de trabalho, bem como reforçar a livre concorrência de mercados numa visão capitalista e neoliberal de existência humana.

A segunda parte do artigo, tratar-se-á das cinco políticas salientadas por Pennycook (1998; 1999; 2001) para melhor elucidar o estatuto da língua num contexto de globalização e internacionalização, ou seja, o lugar que a Língua Portuguesa ocupa em relação à visão mercadológica do cenário globalizado. Dentre essas políticas, há de se destacar: política do conhecimento, política da língua, política do texto, política da pedagogia, política da diferença. Por fim, a terceira parte corresponde à Língua Portuguesa como uma ferramenta que estabelece um contato entre diferentes povos, dentro do contexto da globalização, em tempo de crise da Covid-19, bem como a proposta de uma pedagogia humanizadora para o ensino de língua.

\section{Globalização em tempo de crise da Covid-19: capitalismo e português do Brasil}

Em tempo de crise da pandemia da Covid-19, há de se considerar uma mudança substancial no modus operandi ${ }^{4}$ da sociedade capitalista, condições em que os indivíduos buscam sobreviver frente a esse momento de isolamento social, ou seja, esse termo corresponde às diferentes formas de a sociedade (re)agir frente às situações de diversas ordens, sejam elas políticas, culturais ou econômicas. O termo Covid-19 corresponde ao vírus, denominado Coronavírus - SARS-CoV- $2^{5}$, com origem supostamente na China,

\footnotetext{
${ }^{3}$ No art. 13 reconhece que a língua portuguesa é o idioma oficial da República Federativa do Brasil.

${ }^{4}$ Maneira através da qual uma pessoa ou uma associação, empresa, organização ou sociedade, trabalha ou realiza suas ações. Trata-se do modo utilizado para desenvolver ou realizar alguma coisa; processo de realização (modus operandi, expressão de origem latina). Disponível: https://www.dicio.com.br/modusoperandi/. Acesso em: 17 mai. 2020.

${ }^{5}$ Desde o início de fevereiro, a Organização Mundial da Saúde (OMS) passou a chamar oficialmente a doença causada pelo novo coronavírus de Covid-19. COVID significa Corona Vírus Disease (Doença do Coronavírus), enquanto "19" se refere a 2019, quando os primeiros casos em Wuhan, na China, foram divulgados publicamente pelo governo chinês no final de dezembro. A denominação é importante para evitar casos de xenofobia e preconceito, além de confusões com outras doenças. Disponível: https://portal.fiocruz.br/pergunta/por-que-doenca-causada-pelo-novo-virus-recebeu-o-nome-de-covid-19.
} 
provocou uma pandemia capaz de restringir viagens, o direito de ir e vir, impondo barreiras sanitárias, causando medo, angústia e incertezas.

Denominada Covid-19 pela OMS (Organização Mundial da Saúde), a doença causada pelo vírus, transformou as atividades econômicas, culturais, sociais, educacionais e, principalmente, os sistemas de saúde de grande parte dos países do mundo. A Organização Mundial da Saúde (OMS) declarou, em 30 de janeiro de 2020, que o surto da doença causada pelo novo Coronavírus (COVID-19) constitui uma Emergência de Saúde Pública de Importância Internacional - o mais alto nível de alerta da Organização, conforme previsto no Regulamento Sanitário Internacional. Em 11 de março de 2020, a COVID-19 foi caracterizada pela OMS como uma pandemia.

Estabelece-se aqui uma analogia ao momento de pandemia do novo Coronavírus e o teletrabalho como condição de permanência do modo de produção capitalista. Em outros termos, o teletrabalho tornou-se uma ação diretiva e não interativa, já que o termo "trabalho", oriundo de estudos de Karl Marx (2004), quando do modo de produção capitalista, deve ser orientado à formação humana e não ao "esgotamento" dos seres humanos, a viver à própria sorte, num trabalho intenso e exacerbado de "produção em massa". O homem, nessa visão de mundo extremamente alienada, torna-se refém do sistema capitalista que "impõe" horas de dedicação à realização do trabalho pedagógico ou a pedagogia do teletrabalho ao ponto de transformar a educação numa prática mercantil e precária.

Karl Marx (2004, p.48-49), ao preconizar a alienação do modo de produção capitalista, considera que a produção produz o homem não somente como uma mercadoria, a mercadoria humana, o homem na determinação da mercadoria; ela produz, nesta determinação respectiva, precisamente como um ser desumanizado tanto espiritual como corporalmente - imoralidade, deformação, embrutecimento de trabalhadores e capitalistas. Seu produto é a mercadoria consciente, de-si e auto-ativa, a mercadoria humana. E ainda, "a verdadeira da produção não seria quantos trabalhadores um capital sustenta, mas sim quantos juros ele rende, a soma das poupanças anuais."

Essa reprodução e/ou alienação perpassa também nesse momento ao considerar que o indivíduo se torna uma "mercadoria" de fácil acesso aos interesses econômicos que determinam a forma pela qual o trabalho deva acontecer. Dessa visão neoliberal de mercado, o capitalismo é um sistema opressor em que prevalece a força de trabalho. 0 mercado acelera na medida em que há a produção em massa e alienação do indivíduo que acredita ser fundamental para sua própria sobrevivência, ou seja, acelera-se à procura de trabalho, quando de uma crise de pandemia que assola o mundo.

A crise que se instaurou, quando do surgimento do novo Coronavírus, mais propriamente a Covid-19, já se notava a forma pela qual a sociedade, desde o século XVII, existiu e viveu. Esse consumismo sobretudo acelera a economia dos países que se fartam com o capital. Entretanto, isso ocorre em classes mais privilegiadas cujo poder aquisitivo traz 
a possibilidade de vida farta. O que dizer das classes menos favorecidas em que essa forma de vida se torna até propriamente uma "sobrevida" em muitos casos, ou seja, a sobrevivência humana às custas de auxílio de outrem, vidas fadadas a um meio de subsistência. Boaventura de Sousa Santos (2020, p. 10), em Cruel Pedagogia do Vírus, no capítulo 1, Vírus: tudo o que é sólido se desfaz no ar, ao referir-se à política, assevera:

Em particular, a política, que devia ser a mediadora entre as ideologias e as necessidades e aspirações dos cidadãos, tem vindo a demitir-se dessa função. Se mantém algum resíduo de mediação, é com as necessidades e aspirações dos mercados, esse megacidadão informe e monstruoso que nunca ninguém viu nem tocou ou cheirou, um cidadão estranho que só tem direitos e nenhum dever. É como se a luz que ele projecta nos cegasse.

Boaventura de Sousa Santos (2020, p. 12), em Cruel Pedagogia do Vírus, ao referir-se às colônias europeias, salienta que

(...) o colonialismo dissimulou o seu desaparecimento com as independências das colónias europeias, mas, de facto, continuou metamorfoseado de neocolonialismo, imperialismo, dependência, racismo, etc. Finalmente, o patriarcado induz a ideia de estar moribundo ou enfraquecido em virtude das vitórias significativas dos movimentos feministas nas últimas décadas, mas, de facto, a violência doméstica, a discriminação sexista e o feminicídio não cessam de aumentar.

Com essa passagem pela história, pode-se perceber que o capitalismo permanece frente aos interesses das classes mais prestigiadas da sociedade e a crise traz uma nova realidade. O que era uma economia que alavancava, agora a crise possibilitou uma outra forma de reação da sociedade em função do confinamento. Deixar de sair significa deixar de gastar ou apenas comprar aquilo que for de extrema necessidade à sobrevivência humana. Assim, a superação ocorre quando houver uma forma de pensar diferente em que se valorize o espaço em que vive, não "acostumar-se" mais com o consumismo exacerbado, mas a solidariedade ser o ponto crucial da existência humana, ou seja, o modus operandi da sociedade transformar-se, uma vez que

\begin{abstract}
a nova articulação pressupõe uma viragem epistemológica, cultural e ideológica que sustente as soluções políticas, económicas e sociais que garantam a continuidade da vida humana digna no planeta. Essa viragem tem múltiplas implicações. A primeira consiste em criar um novo senso comum, a ideia simples e evidente de que sobretudo nos últimos quarenta anos vivemos em quarentena, na quarentena política, cultural e ideológica de um capitalismo fechado sobre si próprio e a das discriminações raciais e sexuais sem as quais ele não pode subsistir. A quarentena provocada pela pandemia é afinal uma quarentena dentro de outra quarentena. Superaremos a quarentena do capitalismo quando formos capazes de imaginar o planeta como a nossa casa comum e a Natureza como a nossa mãe originária a quem devemos amor e respeito. Ela não nos pertence. Nós é que lhe pertencemos. Quando superarmos esta quarentena, estaremos mais livres das quarentenas provocadas por pandemias. (SANTOS, 2020, p. 32)
\end{abstract}

Em obra intitulada, "Capitalismo e a Covid-19 - um debate urgente", Souza et al. (2020, p. 14) reforçam que 
é nesta realidade, sob esta forma capitalista de produção e reprodução do ser humano, que nos deparamos com uma pandemia que ameaça a vida: o Coronavírus. Apesar da ideia de que o vírus iguala a todos diante do contágio e da morte, sabemos que não é verdade. A população mais pobre está mais disposta à contaminação e à transmissão da pandemia, sem falar da falta de acesso aos equipamentos de proteção e às terapias necessárias ao tratamento.

Desse modo, quando se considera uma importância maior à livre concorrência, ao mercado e não propriamente à saúde pública diante de uma pandemia, espera-se também uma maneira de acelerar a quantidade de desemprego para melhor demonstrar que a dificuldade não se encontra na quantidade mortes, e sim na grande quantidade de desempregados.

\section{Política linguística e português do Brasil: resistência e/ou reconhecimento no cenário mercadológico da globalização}

O reconhecimento do português como língua internacional e adicional atende, sobretudo, às necessidades de um mercado que exige profissionais qualificados com domínio em diferentes idiomas, dentre eles, o inglês e o espanhol. Entretanto, está aqui uma situação a se refletir: a heterogeneidade da língua ou por que não dizer a diversidade linguística presente na língua portuguesa do Brasil. Os mercados estão adaptados a essa nova realidade ou privilegia-se o português nas suas regras gramaticais? E como adequar a linguagem frente à diversidade linguística, às variantes da língua, sejam elas regional, social, estilística, histórica etc.?

Pensa-se em uma língua adicional adaptada às necessidades do mercado por considerar a língua pela sua sistematização linguística ou possíveis adequações na comunicação oral? Acredita-se na tradição histórica do colonialismo ou em uma heterogeneidade do momento em que a língua se firma como característica de um país de miscigenação, peculiares próprias?

Na realidade, o que se preserva é a língua do colonizador e não a do colonizado, a "europeização da língua" de um povo que dominou e a dominação permanece enraizada na educação linguística. A gramática, com seu grau de importância, persistiu em uma fase em que os ditames das regras do "bem falar" e "bem escrever" existiam como fundamento primordial do estudo da língua. Se a importância era justamente a língua, predominantemente, regida pela normatização linguística, o que compunha sua compreensão era a sua aceitação como pertencente àqueles que detinham o poder pela língua, a "língua do opressor"; apenas detinham essa "língua" os sujeitos que pertenciam às camadas mais privilegiadas da sociedade e não propriamente àqueles que pertenciam às camadas não prestigiadas pela sociedade.

A língua representa um instrumento opressor, quando se considera a influência colonialista de domínio sobre um povo. Essa atitude opressora reflete na maneira pela qual a língua é vista do ponto de vista de sua herança histórica. Diversos estudiosos preconizam o 
poder que a língua exerce na sociedade e isso reflete no modo como os indivíduos agem e (re)agem frente às diferentes situações de uso da língua. Quando se fala em internacionalização da Língua Portuguesa, parte-se da premissa de que as aulas de português para estrangeiros deveriam pautar-se por uma abordagem discursiva de ensino e aprendizagem e essa forma representar as características próprias da língua brasileira.

A questão é a de que a visão mercadológica pode impedir que o português do Brasil se estabeleça e não privilegie o pluralismo presente no país. A discussão aqui fundamenta-se no fato de que não existe apenas uma língua, ou seja, admitir que o Brasil ainda se restringe à raiz colonial. E o que dizer de aulas de português para estrangeiros que têm a pretensão de aprender um idioma sem que haja diferenciações, e sim torná-lo homogêneo e único?

Em reação ao regionalismo existente no Brasil, há de se considerar que cada estado ou região do país recebeu influência europeia para se constituir e falar de estudos de outros idiomas para melhor atuação profissional no mercado de trabalho, assim preconizado pela era da globalização, a Língua Portuguesa necessita de uma identidade linguística para melhor firmar-se como uma língua representativa no cenário mundial e por que não se referir à brasilidade da língua e não apenas pela homogeneidade linguística? O estrangeiro, ao deparar-se com o português do Brasil, identificá-lo ao adaptar-se às suas características próprias.

Oliveira $(2008, \text { p. } 3-4)^{6}$, em estudos sobre "Pluralismo Linguístico", reconhece que

Estado Português e, depois da independência, o Estado Brasileiro, tiveram por política, durante quase toda a história, impor o português como a única língua legítima, considerando-a "companheira do Império" (Fernão de Oliveira, na primeira gramática da língua portuguesa, em 15362). A política linguística do estado sempre foi a de reduzir o número de línguas, num processo de glotocídio (assassinato de línguas) através de deslocamento linguístico, isto é, de sua substituição pela língua portuguesa. A história linguística do Brasil poderia ser contada pela sequência de políticas linguísticas homogeinizadoras e repressivas e pelos resultados que alcançaram: somente na primeira metade deste século, segundo Darcy Ribeiro, 67 línguas indígenas desapareceram no Brasil -- mais de uma por ano, portanto (RODRIGUES, 1993, p. 23). Das 1.078 línguas faladas no ano de 1500 ficamos com cerca de 170 no ano 2000, (somente $15 \%$ do total) e várias destas 170 encontram-se já moribundas, faladas por populações diminutas e com poucas chances de resistir ao avanço da língua dominante.

A característica de uma língua é oriunda da herança de sua colonização. O português, de origem lusitana, ainda traz uma história de dominação e imposição, deixando de lado outras "línguas" ou variantes linguísticas predominantemente do ambiente local. Como bem observa Oliveira (2008), a imposição do português de Portugal para o Brasil, levou à extinção de um número significativo de línguas indígenas, o que denota uma política linguística repressora e/ou opressora, estabelecida em terras brasileiras, quando da sua colonização.

\footnotetext{
${ }^{6}$ Um trabalho conjunto, realizado por estudiosos sobre Pluralismo Linguístico, juntamente em parceira à Organização das Nações Unidas para a Educação, a Ciência e a Cultura (UNESCO) e Instituto de Investigação e Desenvolvimento em Política Linguística (IPOL)
} 
O colonialismo sempre imperou quando das conquistas de terras e as diferentes formas de dominação de povos a tornarem-se colonizados, sujeitos a qualquer forma de discriminação e subjugação.

Acerca disso, Oliveira (2008, p.5-6) preconiza que

não só os índios foram vítimas da política linguística dos estados lusitano e brasileiro: também os imigrantes - chegados principalmente depois de 1850 - e seus descendentes passaram por violenta repressão linguística e cultural. O Estado Novo (1937-1945), regime ditatorial instaurado por Getúlio Vargas, marca o ponto alto da repressão às línguas alóctones, através do processo que ficou conhecido como "nacionalização do ensino" e que pretendeu selar o destino das línguas de imigração no Brasil.

E o que dizer do colonialismo em terras brasileiras, a dominação pelos portugueses e outros europeus que vieram em busca de riqueza, sejam elas o pau-brasil, a cana-de-açúcar e o ouro? O crescimento dos mercados se deu justamente pelo lucro fácil e vasto de um país tropical com muitas riquezas naturais e a extração foi de maneira exacerbada sob o jugo de total dominação e "escravidão" para o enriquecimento dos senhores, grandes proprietários de terras, terras essas pertencentes aos indígenas, antes da vinda dos colonizadores europeus ${ }^{7}$.

Estudos desenvolvidos por Pennycook (2001), em relação às cinco políticas, pode-se dizer que o ensino e aprendizagem da língua sempre esteve voltado ora a políticas de resistência e domínio por meio de práticas colonialistas, ora políticas de interação, intervenção e engajamento por meio de uma postura mais transformadora, crítica e humanizadora. A terceira parte do texto tem por finalidade justamente apresentar reflexões a respeito de aulas de português em duas abordagens diferenciadas: àquelas que ainda insistem em políticas de cunho positivista de ensino de língua, ainda centradas em LA, ou seja, para atender as necessidades do mercado de trabalho, modelo neoliberal de ensino de língua portuguesa como língua adicional; já àquelas, pautadas em LAC, que privilegiam práticas educativas mais humanizadoras de ensino de língua, numa visão mais transformação de construção de identidade e formação humana. Assim, essa parte tratar-seá justamente da Língua Portuguesa como uma ferramenta que estabelece um contato entre diferentes povos, dentro do contexto da globalização, em tempo de crise do Covid-19.

Pennycook (1998), em estudos sobre a abordagem da Linguística Aplicada Critica (LAC) e suas diferentes avanços e perspectivas, considera a visão da LAC, como prática

\footnotetext{
${ }^{7}$ As nações que possuíam colônias de exploração levavam maiores vantagens no comércio internacional. A principal função dessas colônias era fornecer matérias-primas e riquezas minerais para as nações colonizadoras - ou seja, para as metrópoles. Ao mesmo tempo, serviam de mercado consumidor para seus produtos manufaturados. Para o processo de produção e comercialização do açúcar ser lucrativo ao empreendimento colonial, os engenhos introduziram a forma mais aviltante de exploração do trabalho humano: a escravidão, segundo dados extraídos. Disponível em: https://educacao.uol.com.br/disciplinas/historia-brasil/economiacolonial-cana-e-trabalho-escravo-sustentaram-o-brasil-colonia.htm?cmpid=copiaecola. Acesso em: 30 nov. 2020.
} 
problematizadora. O estudioso da linguagem concebe a língua como sendo inerentemente política e o poder, por assim dizer, relaciona-se a questões de classe, raça, gênero, etnia, sexualidade etc. Pennycook ainda reforça que todo conhecimento é político e afirma que requer uma problematização da ideia de língua como mero reflexo da sociedade ou uma ferramenta de manipulação ideológica.

Conforme estudos realizados Freitas \& Pessoa (2012), os autores consideram que Pennycook, ao referir-se às diferentes políticas linguísticas, leva a uma sustentação da língua como um posicionamento crítico do falante do idioma. Os autores salientam que o primeiro trabalho de Pennycook (1990), o estudioso considera que a aprendizagem de línguas está diretamente ligada à manutenção das desigualdades sociais, o que não possibilita uma reflexão maior sobre o contexto em que se vive. Assim postulam Freitas \& Pessoa (2012, p. 6) a respeito do primeiro trabalho realizado por Pennycook (1990):

(...) O autor, então, conclama os(as) linguistas aplicados(as) a examinar a base do conhecimento que produzem, tentando avaliar as formas pelas quais o seu trabalho contribui com a manutenção das hegemonias. Tal postura implica, a nosso ver, o surgimento de uma abordagem crítica para os estudos em LA, especialmente para aqueles relacionados ao contexto de ensino e aprendizagem de línguas, o qual, segundo Pennycook (1990), parece estar mais vinculado à perpetuação do status quo do que a qualquer noção de acesso ao poder (...)

No segundo trabalho, Pennycook (1998) enfatiza a relação entre a língua inglesa e as ideologias coloniais, já que o colonialismo trouxe diferentes formas de pensar, dizer, agir que perpassam pelas diversas culturas e discursos imbuídos de influência colonizadora. Dessa perspectiva, Pennycook (1998) também considera o modo como os discursos se instauram como formas de compreensão da realidade e isso denota o fato de o autor admitir que não existe realidade fora dos discursos e, desses discursos, analisar os possíveis efeitos de sentido. Como o estudioso tem por preocupação a língua inglesa, reconhece que o inglês como "marvellous tongue", denominação para a língua na sua especificidade, chama a atenção para uma reflexão acerca os processos hegemônicos que representam tal denominação, ou seja, os discursos coloniais que determinam formas e práticas de ensino de língua inglesa no mundo.

E, por fim, no último trabalho de Pennycook (1999), reconhece a importância de se considerar uma abordagem crítica no ensino de inglês que, por assim dizer, reflete um trabalho crítico em Linguística Aplicada (LA). Segundo o autor, esse trabalho corresponde propriamente ao poder da língua como uma ferramenta da vida social. Daí a necessidade de um trabalho que busque relacionar o ensino de inglês em relação às questões sociais e políticas, quando do contexto de ensino e aprendizagem de inglês como segunda língua. Entretanto, para o autor, isso não é suficiente para melhor ressaltar outras questões como: poder, acesso, desigualdade e resistência. Com efeito, torna-se necessário politizar o ensino de língua inglesa, não propriamente uma postura esquerdista, e sim refletir sobre as implicações éticas e políticas do professor de inglês em contextos micro e macro. 
Tomando por base tais implicações salientadas por Pennycook (1999), com relação à língua inglesa, considera-se que o ensino de língua portuguesa como língua adicional, voltada a práticas de ensino e aprendizagem para estrangeiro, também perpassa pelas mesmas condições e implicações éticas e políticas. Se, por um lado, o ensino de português traz a raiz colonialista de opressão e desigualdade, considerá-lo como uma língua adicional, é também tratar a língua portuguesa não propriamente como "marvellous langue", e sim "língua do oprimido", já que a origem é a "língua do opressor". Por outro lado, admite-se que os mercados têm necessidade de aprender o português do Brasil e não propriamente o de Portugal. Acerca disso, qual é a função primordial que a Língua Portuguesa deve ocupar como cidadania global, ou seja, cenário histórico, cultural, ético e político?

Pennycook (2001), ao considerar o estatuto da língua, admite que se trata de uma política linguística cujo fio condutor é o da relevância à condição de poder na sociedade. 0 autor apresentou cinco tipos de políticas: política do conhecimento, política da língua, política do texto, política da pedagogia, política da diferença. A primeira política, preconizada pelo estudioso, foi a política do conhecimento. Segundo o autor, todo o conhecimento ou a própria apropriação do conhecimento perpassa por uma política própria de domínio, o que garante ao indivíduo um reconhecimento de tornar-se um ser detentor de uma determinada área, uma capacidade para melhor interagir com os demais pertencentes ao seu grupo ao a outros grupos da sociedade, além de uma visão emancipatória de cidadania constituída na sociedade.

Segundo o autor, a política do conhecimento reflete a relação que se estabelece entre língua, conhecimento e sociedade. Para o estudioso, a LAC implica usar uma língua, posicionar-se ideológica e politicamente, além de assumir uma postura de conhecimento que reflete marcas identitárias, dentre as quais, a classe, o gênero, a sexualidade etc. Com efeito, a política do conhecimento representa uma forma de compreender melhor a práxis social, a língua como prática efetiva. Trata-se de uma visão de língua como prática social, ou seja, o conhecimento sobre e para o mundo social. Em se tratando de política do conhecimento, Freitas e Pessoa (2012, p. 8) ressaltam que:

(...) a ruptura mais notável da LAC no que se refere à política do conhecimento se sustenta na relação entre língua, conhecimento e sociedade. Se, em uma concepção mais tradicional de LA a língua é definida como uma estrutura independente de seus(suas) usuários(as) e do mundo no qual eles(as) vivem, na concepção da LAC usar uma língua significa se posicionar ideológica e politicamente, além de assumir uma postura de conhecimento que reflete nossas marcas identitárias, entre as quais a classe, o gênero, a sexualidade etc. Trata-se, portanto, de uma concepção diferente daquela proposta por Widdowson (1984), segundo o qual a LA deveria se ocupar do estabelecimento de conceitos apropriados ou modelos de língua no domínio pedagógico. Na LAC, a língua não desempenha uma função de modelo, mas de prática social. Uma vez que o conhecimento se torna possível por meio da língua, tanto o conhecimento quanto a língua são definidos, então, como meios que nos possibilitam compreender e transformar as relações sociais. 
A questão identitária de reconhecimento do idioma, como bem lembram os autores, é utilizar a língua para melhor se posicionar política, cultural e ideológica, sobretudo em se tratando de uma língua que se tornou motivo de grande interesse pelos mercados internacionais. A língua adquirir esse estatuto de poder e garantia de maior reconhecimento é também acreditar que o valor do idioma se pauta pelo uso desse idioma. Se, por um lado, os povos de outros países passaram a admitir que a Língua Portuguesa deve ser aprendida, de outro, o povo brasileiro ainda não percebeu a importância de aprendê-la nas suas especificidades. Uma língua "estrangeira" em seu próprio país de origem.

A política da língua traz à baila características do pós-colonialismo (movimento político e cultural), uma vez que corresponde a posturas de resistência e apropriação. Pennycook reforça a ideia de que a LAC desenvolva: uma teoria crítica capaz de lidar com os discursos: uma concepção de língua que extrapole a descrição para sugerir mudanças. E, por último, visão de língua como ferramenta que produz e, ao mesmo tempo, reflete as relações sociais. A política da língua relaciona-se às ações no âmbito social.

A política do texto corresponde a três frentes fundamentais: ao letramento crítico, à análise de discurso crítica e à consciência crítica sobre língua. Para Pennycook (2001), o letramento é um ato político. Por meio dessa política, direciona-se também aos estudos em Análise do Discurso Crítico como correspondente ao aprofundamento dos estudos referentes à Análise do Discurso. Daí compreende-se o letramento como ato político e os textos como processos imbricados dados os contextos de instauração de discursos. Trata-se de um estudo que privilegia as relações sociais presentes nos textos, sobretudo por representar uma produção discursiva na/pela língua. Uma abordagem textual, na perspectiva da LAC, deve considerar uma forma de ação pedagógica por meio da qual o aluno possa transformar-se por meio dos discursos e que essa construção se dê em processos de ensino e aprendizagem da língua. Freitas e Pessoa (2012, p. 9) admitem que

\footnotetext{
(...) a ruptura mais evidente na política do texto, assim como ocorre nas políticas do conhecimento e da língua, refere-se à definição de língua, que, ao ser compreendida como instrumento de ação, passa a ser uma "ferramenta" de grande importância na transformação das relações sociais. Essa primeira ruptura nos leva à outra: a abordagem crítica de textos em LAC por meio de uma concepção crítica de letramento, análise de discurso e consciência sobre língua. Se em reflexões anteriores o foco dos estudos em LA, como se pode notar em Moita Lopes (1996), Widdowson $(1984,2000)$ e McCarthy (2001), era o processo de aquisição de uma segunda língua, agora a aprendizagem de qualquer língua se configura como campo de pesquisa legítimo para os(as) linguistas aplicados(as), visto que o letramento escolar pressupõe o trabalho com a leitura e a produção de textos, a saber, atividades que constroem e refletem as conjecturas de um mundo marcado por ideologias dominantes. Entretanto, faz-se necessário pontuar que a LAC continua a definir a sala de aula como o contexto de maior interesse da LA e a estabelecer maneiras mais efetivas de aprendizagem, ainda que por meio de outros conceitos e à luz de outras teorias.
}

Dessa abordagem textual para o estudo da língua, concebe-se o fato de que o ensino de Língua Portuguesa também requer uma atenção maior quando se trata de diferenças marcantes em relação à "língua portuguesa ou brasileira". As diferentes metodologias de 
ensino propiciam um maior contato com a língua e suas variantes linguísticas, entretanto, cumpre lembrar o papel social que a língua ocupa para interesses hegemônicos e mercadológicos. Ensinar a Língua Portuguesa para estrangeiros é apresentá-la em suas especificidades, musicalidade, estética e estesia ou ensiná-la para ocupar um papel de melhor interação e comunicação entre países que não falam o idioma e têm grande interesse por "negociar" com o Brasil ou propriamente condições de domínio maior dentre do cenário globalizado?

A política da pedagogia corresponde à pedagogia crítica que considera a linguagem como um ato político. Daí a aprendizagem de uma língua referir-se à formação das identidades, ou seja, as posições no discurso. Pensar uma prática social e intervencionista, uma forma de possibilitar um ensino de língua portuguesa como forma de intervenção humanizadora, é também considerar que a língua representa uma mola propulsora de mudanças constantes num processo dialético e dialógico.

Pennycook (2001), ao destacar a política da pedagogia, admite que esta relaciona-se a outros fatores para se constituir, dentre eles: o contexto da sala de aula, as questões de estrutura, agência e resistência, a reprodução social e cultural na educação, a pedagogia crítica e as questões de ética no pós-modernismo. Quando se considera o contexto de sala de aula, o autor reconhece que a LA, por vezes, ainda não leva em conta a importância da sala de aula para promover situações de ensino e aprendizagem e construções identitárias; privilegia-se, pois, o conhecimento linguístico em detrimento das diferentes relações sociais construídas dentro da sala de aula e que refletem na sociedade. Em outros termos, o que ocorre em sala de aula pode representar um avanço em processos de construção de identidade pelo fato de o aluno vivenciar diferentes situações de uso da língua dentre e fora da sala de aula.

A língua corresponde a um ato político e, enquanto tal, representa o indivíduo como falante da língua. Disso resulta a forma pela qual esse ensino e aprendizagem pode acontecer dadas as diversas circunstâncias que impedem o engajamento maior com os processos de construção de conhecimento. Ao salientar sobre as questões de estrutura, agência e resistência, Pennycook (2001) ressalta os principais objetivos de um trabalho crítico: identificar as estruturas sociais e ideológicas que não possibilitam maior reflexão acerca do ensino de língua. $\mathrm{E}$ acrescenta que todas as ações realizadas pelo indivíduo perpassam por questões mais amplas de poder social, ou seja, a língua é a condição do indivíduo de retratar-se, construir-se, identificar-se, porém também reconhecer-se como pertencente a determinada classe social e não poder participar de maneira igualitária em diferentes situações presentes na sociedade.

O autor ressalta a importância de se refletir sobre ambientes de reprodução de relações sociais do que propriamente ambientes voltados à transformação social. Daí as escolas operarem dentro de relações sociais mais amplas e isso pode contribuir com a manutenção do status quo e, dessa forma, atitudes de resistência e possíveis desigualdades sociais. $\mathrm{O}$ autor admite que há necessidade de um trabalho ético em LAC, o que corresponde 
a princípios morais que dimensionam o comportamento como forma de pensar e agir. Freitas e Pessoa (2012, p. 9) salientam que

\begin{abstract}
com base nessas reflexões, vemos que as políticas do conhecimento, da língua e do texto se fundem nas rupturas da política da pedagogia, as quais nos convidam a perceber o conhecimento, a língua e os textos como instrumentos políticos e performativos destinados à transformação social. Se, como afirma Widdowson (1984), a LA deveria buscar abordagens pedagogicamente relevantes para a aprendizagem de línguas, a LAC extrapola o contexto da sala de aula, das regras gramaticais e do desenvolvimento das quatro habilidades comunicativas ao enxergar os(as) alunos(as) e os(as) professores(as) de línguas como sujeitos corporificados e a sala de aula como um ambiente no qual as relações sociais são constantemente reproduzidas e modificadas. Em outras palavras, se antes a busca por uma relevância pedagógica fazia alusão, quase que essencialmente, à adoção de regras pré-concebidas e ao processo de aquisição da língua-alvo em si, sob a ótica da LAC a experiência dos(as) aprendizes deve se somar ao poder que a língua e a educação exercem na (re)construção das práticas sociais.
\end{abstract}

Já a política da diferença corresponde às identidades construídas na e através da língua. Pennycook (2001) reconhece que diversos trabalhos em LA trazem abordagens positivistas de pesquisa, em contextos de ensino e aprendizagem de línguas, quando da aquisição do inglês como segunda língua. $O$ autor, ao defender o fato de a língua construir identidades, equivale dizer que a aprendizagem de uma língua corresponde à formação de identidades de acordo com as posições que o falante do idioma ocupa no discurso. Considera-se de fundamental importância ter uma postura política em relação à aprendizagem de uma língua, dentro e fora da sala de aula, o que envolve também questões de gênero, classe, etnia, raça, idade, conhecimento, sexualidade etc. Freitas e Pessoa (2012, p. 10-11) enfatizam que:

\footnotetext{
Assim como o autor, entendemos que essa postura implica uma refocalização do trabalho crítico transformador, o qual não pode mais ser definido com base em uma discussão racional ou em uma suposta consciência crítica sobre as relações sociais: é preciso reconhecer que as narrativas e a memória operam nas práticas pedagógicas e na pesquisa não somente como possibilidades de se contar histórias ou compartilhar experiências, mas como instrumentos que permitem observar como os nossos corpos e desejos foram/são construídos. (...) Por fim, no que tange à tomada de uma postura transdisciplinar em LAC, Pennycook (2001) afirma que não basta dialogar com outras áreas do conhecimento: é necessário adotar uma postura que compreenda a LAC com um campo de investigação híbrido, isto é, que busca respaldo não somente em áreas afins, como a Educação e a Psicologia, mas também em estudos pós-coloniais
}

Calvet (2007), em seu livro Politiques linguistiques, segundo livro traduzido no Brasil, define a política linguística como um conjunto de escolhas conscientes referentes às relações entre língua(s) e sociedade. ressalta a ligação entre língua e poder e as relações históricas e sociais das línguas, estabelecendo em seu trabalho uma relação permanente entre teoria e prática. Trata-se, com efeito, de uma proposta interessante em torno de um linguista que parte do princípio de que as línguas existem para servir aos homens e não os 
homens para servir as línguas, e que a história destas e constituída pelas histórias de seus falantes.

O autor salienta a importância de uma proposta de política linguística por meio da escola, um planejamento linguístico à implementação prática de uma política de intervenção humana na língua. Isso reforça, ainda mais, o fato de a reflexão estender-se às relações entre as línguas e a sociedade. Em tese, considerava-se, a priori, não ser algo de relevância, predominantemente no campo da Linguística, falar em política linguística. Enquanto a primeira preocupa-se mais com o caráter descritivo de estudos, a segunda, o caráter mais prescritivo e interventor. A predominância dos estudos em linguística relaciona-se mais ao oral; já a política linguística, ao escrito.

A partir das considerações sobre estudos de Pennycook (2001) e estudos realizados por Freitas e Pessoa (2012), além de Calvet (2007), pode-se dizer que o ensino e aprendizagem da língua sempre esteve voltado a políticas de resistência e domínio por meio de práticas colonialistas. Uma abordagem de ensino de língua que privilegia políticas de interação, intervenção e engajamento por meio de uma postura mais transformadora e crítica, é considerar um avanço nos estudos da linguagem na direção de uma educação humanizadora e emancipatória de ensino de língua.

A terceira parte do texto tem por finalidade justamente apresentar reflexões a respeito de aulas de português em duas abordagens diferenciadas: àquelas que ainda insistem em políticas de cunho positivista de ensino de língua, ou seja, para atender as necessidades do mercado de trabalho, modelo neoliberal de ensino de Língua Portuguesa; já àquelas, pautadas em LAC, que privilegiam práticas educativas mais humanizadoras de ensino de língua, numa visão mais transformação de construção de identidade e formação humana. Assim, essa parte tratar-se-á justamente da Língua Portuguesa como uma ferramenta que estabelece um contato entre diferentes povos, dentro do contexto da globalização, em tempo de crise da Covid-19, bem como a proposta de uma pedagogia humanizadora para o ensino de língua.

\section{Português do Brasil e construção de identidade: uma pedagogia humanizadora de ensino de língua}

Determinadas áreas da Linguística, como a Sociolinguística, têm apresentado análises em que se privilegia o estudo de enunciados cujo foco é o de mostrar as diferenças e/ou semelhanças entre as duas modalidades da linguagem (oral e escrita), bem como diferenças entre as variantes da língua, sejam elas de caráter social, histórico, geográfico e estilístico.

O primeiro trabalho que merece destaque, em Sociolinguística, foi o do norte americano William Labov na década de 60. A década de 60 representa um marco para estudos relacionados à função social da linguagem, em que se privilegia a questão da variação linguística e o surgimento das primeiras discussões sobre a heterogeneidade da língua. Labov, em seus estudos sobre a variabilidade linguística, preocupa-se com as 
diferenças entre a língua padrão e não padrão e o que isso representa para a comunicação entre os falantes, ou seja, os estudos remetem-se à questão do preconceito linguístico.

Labov (1972) preocupou-se com a relação entre língua e sociedade e, dessa perspectiva, o estudo volta-se aos fatores determinantes linguísticos e extralinguísticos à análise de comunidades de fala. Trata-se de um estudo empírico em que o autor privilegia a análise da competência linguística de falantes do Gueto dos Estados Unidos e as diferenciações existentes nessas comunidades de fala para melhor elucidar a importância do estudo da língua, compreendendo-a como um fator de preconceito e, ao mesmo tempo, identidade e características próprias de comunidades de fala. Lagares (2018), em estudos relacionados a políticas linguísticas, ressalta que

(...) nos anos 1960, William Labov, fundador da sociolinguística variacionista, fez do seu trabalho descritivo, focado na explicação dos processos de mudança linguística, um instrumento de intervenção sociopolítica, ao testemunhar a favor do uso do inglês afro-americano escolas do Harlem, em Nova York. Esse engajamento com os instrumentos da descrição estrutural a "legitimidade" das suas práticas linguísticas, constitui um momento importante na tomada de consciência da relevância social da própria pesquisa, independentemente do olhar teórico sobre a língua que a animava. A reflexão acerca dos processos sociais de mudança linguística leva Labov a concentrar a atenção também nas intervenções provocadas pela imposição da norma-padrão, em relação às representações e às práticas linguísticas.

Marcos Bagno (2002, p. 32), em estudos sobre as variações linguísticas do português do Brasil, acredita ser de fundamental importância

(...) estimular, nas aulas de língua, um conhecimento cada vez maior e melhor de todas variedades sociolinguísticas, para que o espaço da sala de aula deixe de ser o local para o estudo exclusivo das variedades de maior prestígio social e se transforme num laboratório vivo de pesquisa do idioma em sua multiplicidade de formas e usos.

O estudioso da linguagem admite que o Brasil apresenta uma interpenetração das diferentes variedades regionais, estilísticas, sociais e isso relaciona-se às migrações populacionais entre as diversas regiões, o que leva à difusão dos falares identificados geograficamente pela dialetologia brasileira existente no país, como é o caso do falar nordestino. Em outro estudo, Bagno (2003, p.18) assevera que:

(...) "a língua" como "essência" não existe: o que existe são seres humanos que falam línguas. A língua não é uma abstração: muito pelo contrário, ela é tão concreta quantos os mesmos seres humanos de carne e osso que se servem dela e dos quais é parte integrante. Se tivermos isso sempre em mente, poderemos deslocar nossas reflexões de um plano abstrato - "a língua' - para um plano concreto - os falantes da língua.

O autor reconhece que a língua existe dentro da realidade histórica, cultural, social, ou seja, os seres humanos que fazem uso da língua, seja na modalidade oral ou escrita da linguagem, entretanto, ainda há de se conceber uma concepção tradicional no ensino de 
língua, tendo em vista tratar-se de uma abordagem que privilegia a língua como um produto acabado.

Sabe-se que as políticas linguísticas apontam para o crescimento da Língua Portuguesa, neste século, desde 2006. O Acordo Ortográfico, neste início de século, é a prova disso. O mais interessante é que a Língua Portuguesa crescente no mundo e a Língua Portuguesa do Brasil, dado o interesse econômico pelo país por grandes potências mundiais. O que dizer de um idioma que sofre modificações para atender à demanda do mercado, uma vez que outros povos sempre admitiram a Língua Portuguesa como uma das línguas com grau de complexidade para ser aprendida. O Acordo Ortográfico da Língua Portuguesa buscou uma homogeneidade linguística entre os povos, falantes do português, sem sequer compreender as variantes ou dialetos de cada país.

Aqui entra uma questão bastante relevante quando se fala em modalidade da linguagem e suas características próprias. Há de se considerar diferentes reformas ortográficas no país e isso reflete a não predominância da heterogeneidade linguística presente no Brasil. Sabe-se que o Brasil passou por várias reformas ortográficas. A primeira reforma ortográfica data de 1911 cujo foco foi o de uniformizar e simplificar a escrita, porém não foi relativa ao Brasil. Em 1915, a Academia Brasileira de Letras buscou uniformizar a ortografia à portuguesa. Já, em 1919, a Academia Brasileira de Letras revoga a sua resolução de 1915.

O último acordo ortográfico trouxe implicações de cunho político, uma vez que foi criado com a intenção de unificação linguística entre os países de idioma da Língua Portuguesa. Esse acordo foi assinado em 1990 e passou à aprovação em 1995, denominado, Acordo Ortográfico da Língua Portuguesa ou Novo Acordo Ortográfico. O acordo foi implementado em 2010, em que os livros didáticos sofreram modificações, assim também os textos veiculados virtualmente. Em 2013, passou a ser obrigatório sua utilização, segundo as regras estabelecidas, para o ensino de língua. Oliveira (2013), em artigo intitulado, "Política linguística e internacionalização: a língua portuguesa no mundo globalizado do século XXI", reconhece que

dadas estas pressões, entre outras, podemos propor que o Acordo Ortográfico da Língua Portuguesa de 1990 (AO90) assinado por todos os países de língua oficial portuguesa e ratificado por todos menos Angola e Moçambique, e sua entrada em vigor no Brasil, a partir de 2009 e em Portugal a partir de 2011, bem como das primeiras medidas de implementação em Cabo Verde, em 2012, foi o primeiro indício do aumento das pressões por uma normatização convergente, Muito mais do que uma simples reforma ortográfica, o AO90 propõe uma profunda mudança na perspectiva de gestão da língua pela superação da perspectiva puramente nacional a que se acostumaram amplos setores da vida cultural de Portugal e Brasil e pela abertura de uma perspectiva nova que conduz e tem conduzido ao desenvolvimento conjunto de instrumentos ou dispositivos de normalização linguística, uma vez instaurada a prática e as metodologias de trabalho compartilhado, que otimiza o investimento e reparte os lucros. O AO90 explicita uma norma (neste caso ortográfica) negociada entre todos os países, dos maiores aos menores, em regime de paridade, implicando na corresponsabilidade de todos para com a língua comum. (OLIVEIRA, 2013, p. 424-425) 
Em Pedagogia do Oprimido, Paulo Freire (1987, p. 32) propõe um método que privilegia a educação como prática de liberdade. $\mathrm{O}$ autor acredita que, em sociedades cuja dinâmica seja a dominação, a pedagogia dominante é a das classes dominantes. $O$ educador ressalta que a educação se torna "desumanizadora" na medida em que há "opressor e oprimido", uma vez que

o grande problema está em como poderão os oprimidos, que "hospedam" o opressor em si, participar da elaboração, como seres duplos, inautênticos, da pedagogia de sua libertação. Somente na medida em que se descubram "hospedeiros" do opressor poderão para contribuir para o partejamento de sua pedagogia libertadora. Enquanto vivam a dualidade na qual ser é parecer e parecer é parecer com o opressor, é impossível fazê-lo. A pedagogia do oprimido, que não pode ser elaborada pelos opressores, é um dos instrumentos para esta descoberta crítica - a dos oprimidos por si mesmos e a dos opressores pelos oprimidos, como manifestações da desumanização.

Ao conceber a educação como desumanizadora, Freire (1987) reconhece a importância de uma educação em que haja uma situação igualitária em relação à liberdade e isso torná-la uma superação e não opressão. O diálogo, para Freire, é a condição de prática de liberdade, uma vez que se inicia por meio de uma "inquietação" em torno do conteúdo programático da educação. Assim assevera Freire (1987, p. 57):

Falar da realidade como algo parado, estático, compartimentado e bemcomportado, quando não falar ou dissertar sobre algo completamente alheio à experiência existencial dos educandos vem sendo, realmente, a suprema inquietação desta educação. A sua irrefreada ânsia. Nela, o educador aparece como seu indiscutível agente, como o seu real sujeito, cuja tarefa indeclinável é "encher" os educandos dos conteúdos de sua narração. Conteúdos que são retalhos da realidade desconectados da totalidade em que se engendram e em cuja visão ganhariam significação. A palavra, nestas dissertações, se esvazia da dimensão concreta que devia ter ou se transforma em palavra oca, em verbosidade alienada e alienante. Daí que seja mais som que significação e, assim, melhor seria não dizê-la.

Em Pedagogia da autonomia, Freire (1997, p. 29) retoma a educação bancária de transferência de conhecimento e admite que o ato de ensinar requer um rigor metodológico e, ao mesmo tempo, libertador em relação ao discurso bancário, uma vez que

(...) é exatamente neste sentido que ensinar não se esgota no "tratamento" do objeto ou do conteúdo, superficialmente feito, mas se alonga à produção das condições em que aprender criticamente é possível. E essas condições implicam ou exigem a presença de educadores e educandos criadores, instigadores, inquietos rigorosamente curiosos, humildes e persistentes. (...) Só assim podemos falar realmente de saber ensinado, em que o objeto ensinado é apreendido na sua razão de ser e, portanto, aprendido pelos educandos.

Proporcionar um ambiente favorável de ensino, em que o educando aprende e desenvolve a criticidade, desperta a criatividade, é garantir o exercício pleno de sua 
cidadania. Transformar o ato de ensinar em um ato dialógico, epistemológico e interacional representa assumir o compromisso com uma educação emancipatória.

É nesse sentido também que a dialogicidade verdadeira, em que os sujeitos dialógicos aprendem e crescem na diferença, sobretudo no respeito a ela, é a forma de estar sendo coerentemente exigida por esses seres que, inacabados, assumindo-se como tais, se tornam radicalmente éticos. (...)A boniteza de ser gente se acha, entre outras coisas, nessa possibilidade e de nesse dever de brigar. Saber que devo respeito à autonomia e à identidade do educando exige de mim uma prática em tudo coerente com este saber (idem, p. 67).

Nunes (2019, p.39), em seu capítulo Educação em direitos humanos no Brasil atual: fundamentos políticos pedagógicos e emancipatórios possíveis, enfatiza o processo de humanização da Educação, ao afirmar que:

Temos repetido que a Educação é seguramente a mais destacada das dimensões
sociais. Educar, em última instância, consiste em produzir o homem para a vida em
sociedade. Educar é hominizar-se, fazer-se homem, fazer-se pessoa. Mas, ao
mesmo tempo, educar é projetar as características humanas no mundo, na
realidade natural e na civilização constituída pela marcha histórica de toda a
comunidade humana. Assim, educar significa manejar um duplo processo:
hominizar-se, isto é, fazer-se homem humanizar-se, isto é, fazer o mundo à medida
do homem! Esta é a tarefa da educação no tempo em que vivemos. A sociedade da
informação, tal como é chamada a nossa época, ou ainda a sociedade do
conhecimento, em outras denominações, quer ainda a era tecnológica, em alusões
performáticas, despidas de critérios éticos e políticos, transforma a educação, em
cada uma de suas peculiaridades, necessitam buscar parâmetros éticos, estéticos e
pedagógicos humanistas e humanizadores.

O filósofo considera uma "Pedagogia Humanizadora" em que a premissa é a de que educar é a mesma ação que humanizar. A condição humana é uma condição aprendida e cada indivíduo se constitui como humano na relação com os outros, na relação com o mundo. Educar e humanizar representam o mesmo processo. Daí não causar estranheza uma proposta de educação como humanização. Para o estudioso, essa concepção humanizadora de educação retoma as origens da compreensão da educação como constituinte antropológica. Dessa forma, nenhum ser humano pode abdicar de educar e, neste sentido, de humanizar o mundo e a sociedade. Por fim, a tarefa de educar e de humanizar é a base da cultura, da política e da história social.

Pensar em uma educação humanizadora em que se leve em conta a condição humana e não apenas interesses hegemônicos e mercadológicos é também compreender que a língua pode ser aprendida por outros povos, para além do capital, analogia a Marx (2004). Para uma humanização e transformação de seres pertencentes a diferentes etnias, culturas, enxergar a língua numa cidadania global em que os povos possam aprendê-la pela sua riqueza, heterogeneidade, musicalidade e estética.

Em relação à Língua Portuguesa, até que ponto a aprendizagem corresponde a todos e pertence a todos os "estrangeiros" ou apenas aos indivíduos com interesses econômicos para a aprendizagem de um idioma que atenda às necessidades do mercado internacional? A educação torna-se desumanizadora na medida em que não é direcionada àqueles oriundos 
de determinados países que não pertençam aos interesses hegemônicos de uma sociedade de deveres e não propriamente direitos garantidos.

Em momento de pandemia da Covid-19, há necessidade de políticas públicas de incentivo ao ensino de língua, políticas linguísticas de estudo do novo cenário e, com relação à importância da Língua Portuguesa como uma língua adicional, diretrizes que melhor estabeleçam a aprendizagem da língua a outros povos, finalidades, implicações e inovações no que tange à diversidade linguística do português do Brasil.

Com base nessas considerações, a pretensão é a de apresentar uma proposta de intervenção às aulas de português para estrangeiros, residentes ou não no país. Parte-se da premissa de que uma proposta para uma educação humanizadora deve recorrer-se a algumas questões norteadoras, de acordo com as seguintes diretrizes: O que se privilegia no processo de ensino / aprendizagem da Língua Portuguesa? Qual é a formação docente adequada a essa nova realidade? Quais são os objetivos da aprendizagem da Língua Portuguesa para fins mercadológicos de ensino, quando do ensino de língua para fins específicos?

Acredita-se em uma pedagogia humanizadora para o ensino de Língua Portuguesa, a partir de alguns eixos norteadores à elaboração de uma proposta curricular: descolonização global sobre dimensões (dimensão nacional, política, ética e cultural), internacionalização da língua, plurilinguismo funcional e cenário da Covid-19. Para tanto, a proposta deve iniciar-se pelos aspectos peculiares da realidade brasileira, cultura, crença, costumes, valores, ideologias e depois consolidar uma política linguística de implementação de aulas de português para estrangeiros. Essas aulas não devem constituir-se apenas por meio de interesses econômicos, mas sim em contexto escolar em que haja alunos, de outras nacionalidades, possam receber orientações como algo enriquecedor e não apenas opressor.

Parte-se da premissa de que educar é uma via de mão dupla, ou seja, educar aquele que é pertencente ao seu país e necessita de uma educação de qualidade e àquele que é oriundo de outro país e aprende a Língua Portuguesa. Acreditar em uma abordagem discursiva e humanizadora é também compreender que a língua é uma ferramenta de ascensão social e transformação.

A emancipação do indivíduo remete-se à condição do indivíduo que, por assim dizer, relaciona-se à condição de aprendizagem. A proposta de uma pedagogia humanizadora é a de possibilitar que a língua seja reconhecida pelas suas especificidades como o "português do Brasil". Daí a necessidade de uma adequação às diretrizes estabelecidas para o ensino de língua como língua adicional. Considerar a língua como adicional é compreendê-la não apenas como uma língua a serviço de uma visão neoliberal, mas sim reconhecê-la como construção identitária de um povo com uma diversidade linguística e características peculiares. 


\section{Considerações finais}

O artigo teve a pretensão de apresentar a questão da internacionalização da Língua Portuguesa como língua adicional e a importância fundamental no cenário da globalização. Sabe-se que o ensino de língua sempre esteve voltado a políticas linguísticas de adoção dos ditames do colonialismo. A história de diferentes correntes de estudo da linguagem demonstra essa forma de compreender a língua pela sua raiz colonial. Desde o surgimento das primeiras gramáticas já se pensava numa "europeização linguística", o que contribuiu para uma abordagem mais de cunho positivista e tradicional, quando do ensino de gramática como um fim em si mesmo.

Nesse artigo, pôde-se notar que a Língua Portuguesa passou a adquirir um estatuto diferenciado para atender ao mercado globalizado. Diferentes povos, dadas as diferenças de nacionalidades, almejam aprendê-la na tentativa de consolidar maior autonomia, quando da concorrência em diferentes mercadores internacionais. Desse ponto de vista, a língua passa a ser considerada uma "mercadoria" a ser melhor negociada e por que não dizer adquirida pela aprendizagem.

Com a crise da Covid-19, os mercados sofreram uma queda e isso também influenciou na livre concorrência o que, de certo modo, também influenciou na aprendizagem da Língua Portuguesa. Por outro lado, com a situação de crise, os povos necessitam comunicar-se e isso pôde facilitar maior acesso aos diferentes idiomas, ao ponto de um idioma imbricar-se em outro, haja vista as palavras do inglês à Língua Portuguesa: Covid-19, aulas on-line, lockdown etc.

Sob essa ótica, o artigo apresentou três partes: a primeira parte tratou-se da globalização em tempo de crise da Covid-19, como forma de mostrar o modo de produção capitalista, na condição de força de trabalho, bem como reforçar a livre concorrência de mercados numa visão capitalista e neoliberal de existência humana. A segunda parte do artigo, tratou-se da política linguística, salientada por Pennycook (1998; 1999; 2001) e Calvet (2007), para melhor elucidar o estatuto da língua num contexto de globalização e internacionalização. Por fim, a terceira parte, a Língua Portuguesa como uma ferramenta que estabelece um contato entre diferentes povos, dentro do contexto da globalização, em tempo de crise da Covid-19, bem como uma proposta humanizadora e emancipatória de intervenção no ensino de Língua Portuguesa como língua adicional.

Em estudos realizados, Souza (2020, p.16) admite que

os oprimidos de hoje são os pobres, as maiores vítimas deste sistema que acorrenta, explora e leva à morte. Esta diferença de classe é gritante no Brasil e atualmente a desigualdade social é uma das maiores do mundo. Há uma imensa massa de desempregados e miseráveis vendendo sua força de trabalho por um salário de fome, enquanto poucos, detentores dos meios de produção e do capital, acumulam riquezas e influenciam, segundo os interesses econômicos, não só os poderes da república, mas uma grande massa disposta, pela cegueira, a viver segundo os interesses deste poder. 
Diante do cenário de pandemia da Covid-19, os oprimidos são aqueles que vivem à margem da sociedade, já que uma grande parcela da população se encontra à deriva, na tentativa de buscar melhores condições econômicas de sobrevivência dadas as situações adversas oriundas do momento de crise. E o que dizer do lugar ocupado pela Língua Portuguesa, no mercado internacional, dentro do cenário histórico, cultural, ético e político de cidadania global, considerando a língua uma ferramenta de dominação e resistência e, ao mesmo tempo, interação, humanização e acolhimento?

\section{Referências}

BAKHTIN, M. (1929). Marxismo e filosofia da linguagem. São Paulo: HUCITEC, 1992.

BAGNO, M.; STUBBS, M.; GAGNÉ, G. Língua materna - letramento, variação \& ensino. São Paulo, Parábola: 2002.

BAGNO, M. A norma oculta - língua \& poder na sociedade brasileira. São Paulo: Parábola: 2003.

BRASIL. Constituição da República Federativa do Brasil de 1988. Disponível em: http://www.planalto.gov.br/ccivil_03/constituicao/constituicao.htm. Acesso: 28 mar. 2020.

CALVET, L. As Políticas Linguísticas. Florianópolis e São Paulo: Ipol/Parábola, 2007.

Economia colonial - Cana e trabalho escravo sustentaram o Brasil colônia. UOL. Disponível: https://educacao.uol.com.br/disciplinas/historia-brasil/economia-colonial-cana-e-trabalhoescravo-sustentaram-o-brasil-colonia.htm?cmpid=copiaecola. Acesso em: 30 nov. 2020.

FREIRE, P. Pedagogia do oprimido. Rio de Janeiro: Paz e Terra, 1987.

FREIRE, P. Pedagogia da autonomia. São Paulo: Paz e Terra, 1997.

FREITAS, M. T. de U.; PESSOA, R. R. Rupturas e continuidades na Linguística Aplicada Crítica: uma abordagem historiográfica. Calidoscópio, v. 10, n. 2, p. 225-238, 2012.

MARX, K. Manuscritos Econômico-Filosóficos. São Paulo: Boitempo, 2004.

NUNES, C. Educação em Direitos Humanos no Brasil Atual: Fundamentos Políticos e Práticas Pedagógicas Possíveis. In: NUNES, C. A.; GOMES, C. (Orgs.). Direitos Humanos: Educação e Democracia. Campinas: Brasílica, 2019. p. 35-52.

LAGARES, C. X. Qual política linguística - desafios glotopolíticos contemporâneos. São Paulo: Parábola, 2018.

OLIVEIRA, G. M. Plurilinguismo no Brasil. Organização das Nações Unidas para a Educação, a Ciência e a Cultura (UNESCO) e Instituto de Investigação e Desenvolvimento em Política Linguística (IPOL). Brasília, 2008.

OLIVEIRA, G. M. Política linguística e internacionalização: a língua portuguesa no mundo globalizado do século XXI. Trab. Ling. Aplic, Campinas, n. 52, v. 2, p. 409-433, 2013.

Por que a doença causada pelo novo vírus recebeu o nome de Covid-19? 2020. FIOCRUZ. Disponível: $\quad$ https://portal.fiocruz.br/pergunta/por-que-doenca-causada-pelo-novo-virusrecebeu-o-nome-de-covid-19. Acesso em: 30.nov.2020. 
SANTOS, B. S. A crise da pedagogia do vírus. Coimbra/Portugal: Edições Almedina, 2020.

SOUSA, J. N. Capitalismo e a Covid-19 - um debate urgente. In: CASTRO, Daniel; SENO, Danillo Dal; POCHMANN, M. (Orgs.). Covid-19 e capitalismo: uma visão. São Paulo: 2020. Disponível: http://abet-trabalho.org.br/wpcontent/uploads/2020/05/LIVRO.CapitalismoxCovid19.pdf. Acesso em: 17 mai. 2020.

Recebido em: 03/08/2020. Aceito em: 22/10/2020. 